\title{
ANÁLISE DAS AÇÓES DA EMPRESA PETRÓLEO BRASILEIRO S.A A PARTIR DAS PERCEPÇÓES DE RESPONSABILIDADE SOCIAL EMPRESARIAL (RSE) PROPOSTAS POR CARROLL
}

\author{
ANALYSIS OF THE ACTIONS OF THE COMPANY PETRÓLEO BRASILEIRO S.A FROM THE \\ PERCEPTIONS OF CORPORATE SOCIAL RESPONSIBILITY (CSR) PROPOSED BY CARROLL
}

Fabíola Besen (iD

Universidade Estadual do Oeste do Paraná, PR, Brasil, fabiolagracielebesen@gmail.com

\section{Giovane dos Santos}

Universidade Estadual do Oeste do Paraná, PR, Brasil, giovane771@hotmail.com

Resumo: O presente estudo tem como objetivo geral analisar as açôes desenvolvidas pela estatal brasileira Petróleo Brasileiro S.A. através das percepçôes de Responsabilidade Social Empresarial proposta por Archie B. Carroll (1979; 1991). A metodologia utilizada para realização da pesquisa foi baseada na análise documental dos relatórios administrativos e de sustentabilidade, considerando os anos de 2016 a 2018 , utilizando-se de pesquisa bibliográfica do tipo descritiva, com método dedutivo e abordagem qualitativa e quantitativa, sendo um estudo de caso de finalidade pura. Através da análise dos relatórios, os resultados apontaram que nos anos analisados ao menos três iniciativas cumpriram com todas as perspectivas proposta pela Teoria de Carroll $(1979 ; 1991)$, destacando que em todos os anos o aspecto ético foi o que obteve maior evidenciação entre as ações desenvolvidas, seguido pela perspectiva econômica, legal e filantrópica.

Palavras-chave: Responsabilidade social. Evidenciação. Ética.

\begin{abstract}
The present study aims to analyze the actions developed by the Brazilian state-owned company Petróleo Brasileiro SA through the perceptions of Corporate Social Responsibility proposed by Archie B. Carroll (1979; 1991). The methodology used to carry out the research was based on documentary analysis administrative and sustainability reports, considering the years 2016 to 2018, using descriptive bibliographic research, with deductive method and qualitative and quantitative approach, being a pure purpose case study. Through the analysis of the reports, the results showed that in the years analyzed, at least three initiatives fulfilled all the perspectives proposed by Carroll's Theory (1979; 1991), highlighting that in all years the ethical aspect was the one that obtained the greatest disclosure among the actions developed, followed by the economic, legal and philanthropic perspective.
\end{abstract}

Keywords: Social Responsibility. Disclosure. Ethic. 


\section{Introdução}

A busca constante pela lucratividade e desenvolvimento das empresas tem se difundido não somente pela cobrança de seus acionistas na geração de lucro e retorno financeiro, mas também pela preocupação da administração em alinhar o crescimento das empresas com o retorno esperado pela sociedade. Essa mudança trouxe um novo olhar para os executivos, os quais teriam que buscar um equilíbrio entre o retorno aos acionistas e a obrigação de atender aos crescentes grupos que reivindicavam um comportamento ético por parte dos gestores perante a sociedade (CARROLL, 1991).

Esse reconhecimento traz às organizaçóes uma postura mais responsável de suas açôes em favor do corpo social, além de transmitir uma imagem de empresa não somente preocupada com o retorno financeiro, mas também com o retorno à sociedade. Esse debate sobre a Responsabilidade Social Empresarial (RSE) vem sendo discutido desde meados dos anos 1960 em países da Europa e nos EUA através do surgimento de movimentos sociais ativistas, os quais defendiam uma postura mais ampla de responsabilidade corporativa por parte das organizações (CARROLL, 1991).

Embora esse assunto venha sendo discutido desde meados dos anos 60, segundo Tenório (2015), o tema a respeito de responsabilidade social empresarial é contemporâneo, pois contempla questóes que envolvem a preocupação da organização com a sociedade e meio ambiente, através da inserção de ações sociais no plano de negócio da organização.

A finalidade e conceito de responsabilidade social vem sendo construído juntamente com a evolução do conceito de organização, expandindo o relacionamento além do ambiente interno as empresas, incluindo uma inter-relação com a sociedade (MATSUSHITA, 2004).

A Responsabilidade Social Empresarial descrita por Archie B. Carroll, base para esse estudo tem por primícias a caracterização da RSE, e sua conciliação com as obrigaçóes das organizaçóes perante seus acionistas, bem como as obrigaçóes perante a sociedade. Neste contexto Carroll (1991) apresenta a Pirâmide de Responsabilidade Social na qual sugere que através desta, será enquadrada toda gama de responsabilidade corporativa, constituída pelas responsabilidades econômicas, legais, éticas e filantrópicas (CARROLL, 1979;1991).

A utilização da temática sobre RSE possui grande relevância no contexto nacional, visto o crescente número de trabalhos científicos desenvolvidos na área, como por exemplo os estudos de Pereira (2016), Nakayama e Teixeira (2012) e Gomes, et al. (2015), nota-se também o crescente número de estudos anteriores que utilizam as percepçóes de RSE descritas por Carroll (1979;1991), como por exemplo os estudos de Bittencourt e Carrieri (2005) e Tozzo, Igarashi, Igarashi e Silva (2017).

Para desenvolvimento da pesquisa optou-se pela escolha e análise dos dados da maior empresa de exploração e produção de petróleo do país, a Petróleo Brasileiro S.A (Petrobrás) empresa estatal de economia mista, com capital aberto, a qual possui o Governo Brasileiro como acionista majoritário. A empresa foi criada pelo então presidente do Brasil Getúlio Vargas, no ano de 1953 e desde então vem expandindo sua atuação no setor, atualmente a estatal brasileira é líder mundial na exploração de petróleo em águas profundas e ultra profundas (PETROBRÁS, 2018) 
A escolha deste segmento mostra-se relevante por se tratar de um setor de grande importância econômica para o país, segundo dados da Agência Nacional de Petróleo, Gás Natural e Biocombustível - ANP, a participação do setor Petroleiro e Gás correspondeu a 13\% do PIB (Produto Interno Bruto) do país. No ano de 1998 o país tinha aproximadamente 14 bilhóes de barris em reservas totais de petróleo, passando a ter cerca de 23 bilhóes de barris de reservas totais no ano de 2016. A produçáo de petróleo cresceu consideravelmente neste período, saltando de uma produção diária de 970 mil barris por dia no ano de 1998 para 2,6 milhóes de barris por dia no período de janeiro a novembro de 2017 (ANP, 2018).

A partir do exposto acima, a pesquisa busca responder o seguinte questionamento: Com base na teoria proposta por Carroll (1979;1991), em quais açóes desenvolvidas pela empresa Petróleo Brasileiro S.A é possivel evidenciar as percep̧̧ôes de Responsabilidade Social Empresarial?

Desta forma, o presente estudo tem como objetivo geral analisar as açóes desenvolvidas pela estatal brasileira Petróleo Brasileiro S.A. através das percepções de Responsabilidade Social Empresarial proposta por Archie B. Carroll (1979;1991).

A abordagem da pesquisa demonstra-se relevante pela importância e atualidade do tema para a sociedade, gestores e investidores preocupados com a imagem da organização, bem como pela complexidade proveniente da exploração do petróleo e riscos inerentes a esta atividade que podem gerar graves prejuízos ambientais e econômicos a sociedade. Contudo o estudo se mostra relevante pois busca sintetizar dados contidos em relatórios, organizando as informaçôes para democratizar e facilitar a compreensão e acesso dessas informaçôes a sociedade.

Esta pesquisa possui como base o estudo desenvolvido por Tozzo, et al. (2017), que utilizou as percepçóes propostas por Carroll para análise dos relatórios de empresas do setor de energia elétrica e verificar se as perspectivas de Carroll $(1979 ; 1991)$ são explicitadas nesses relatórios e em qual se realizaram os maiores investimentos financeiros.

O estudo está estruturado da seguinte forma: introdução, referencial teórico, metodologia de pesquisa, análises de dados, consideraçóes finais e referências. A introdução aborda o tema da pesquisa e seu problema, objetivo e objetivos específicos bem como a justificativa de sua realização. O referencial teórico traz alguns conceitos utilizados na pesquisa, estudos relacionados a RSE e percepçóes sobre Responsabilidade Social proposta por Carroll. A parte intitulada metodologia de pesquisa discorre sobre o tipo de pesquisa e sua abordagem, o método adotado, a técnica empregada, a forma de coleta e tabulaçáo dos dados, bem como o universo de pesquisa. A análises de dados apresenta as informaçóes encontradas nos relatórios, concordância com as percepçóes propostas por Carroll (1979;1991) e demais assuntos pertinentes ao estudo. Quanto as consideraçóes finais, são listados os objetivos do estudo e seu cumprimento, apresentação das limitaçóes encontradas durante a coleta e análise dos dados, finalizando com as referências utilizadas para realização da pesquisa.

\section{Referencial teórico}

Buscando fundamentar as análises e conclusóes, fez-se necessário o levantamento da literatura acerca dos conceitos que dizem respeito a Responsabilidade Social Empresarial, práticas de RSE, percepçóes sobre Responsabilidade Social Empresarial proposta por Carroll e estudos relacionados. 


\subsection{Responsabilidade Social Empresarial}

Com o surgimento das ciências administrativas e a profissionalização dessa atividade nos Estados Unidos no século XX, entre 1900 a 1960, o debate sobre a dimensão social das empresas teve seu início. Inicialmente, o conceito de Responsabilidade Social esteve apoiado nos princípios básicos da filantropia, governança e manifestaçôes paternalistas corporativos (Carroll, 1979;1991). A partir da década de 1970, segundo George (1987), debates sobre Responsabilidade Social das organizaçóes e sua influência na economia política e nos limites do crescimento surgiram fazendo com que empresas passassem a responder não somente pela rentabilidade, mas também por obrigaçóes de maior amplitude, constituindo formalmente a ética empresarial.

Segundo Benedicto, Rodrigues e Penido (2008), a expressão "responsabilidade social” foi utilizada pela primeira vez no manifesto de 120 indústrias ingleses, o qual mencionava que a "responsabilidade dos que dirigem a indústria é manter um equilíbrio justo entre os vários interesses dos públicos, dos consumidores, dos funcionários, dos acionistas”. Seguindo o mesmo conceito, Bowen (1957, p. 14) descreve que "à obrigação do homem de negócio de adotar orientações, tomar decisôes e seguir linhas de ação que sejam compatíveis com os fins e valores da sociedade”.

Para Ferrell, Fraedrich e Ferrell (2001) a responsabilidade social consiste na obrigação da empresa em maximizar seu impacto positivo sobre os clientes, sociedade, colaboradores e em minimizar possíveis impactos negativo. Neste contexto de acordo com Melo Neto e Fróes (1999, p. 84) a responsabilidade de uma empresa, "é vista como um compromisso da empresa com relação a sociedade e à humanidade em geral, é uma forma de prestação de contas do seu desempenho, baseada na apropriação e uso de recursos que originalmente não lhe pertencem”.

De acordo com Ashley (2002, p. 98) Responsabilidade Social é o compromisso que a empresa deve ter junto a sociedade, agindo de forma ativa e coerente de acordo com a sua atribuição, impactando de forma positiva na comunidade no qual está inserida, dando sua contribuição, mesmo que de forma indireta para desenvolvimento sustentável da sociedade. Ou seja, estando presente na colaboraçáo de açôes que visam contribuir com o crescimento, mesmo que essas açôes não estejam ligadas diretamente com o papel organizacional da empresa.

Para Camargo (2005), a RSE é uma estratégia a longo prazo no qual a organização busca os resultados amparada a preocupaçáo de trazer o mínimo de impacto social e ambiental as comunidades aonde estấo instaladas as atividades empresariais.

Segundo Andrade, Gosling e Xavier (2010), a Responsabilidade Social Empresarial possui como objetivo a conquista do sucesso comercial pautada por decisóes baseadas nos valores éticos importantes para a sociedade e a organização, com respeito aos clientes, fornecedores, funcionários, comunidade e ao meio ambiente.

Segundo o Instituto Ethos (2007), as práticas de responsabilidade social empresarial dizem respeito à relaçáo ética e transparente das empresas com a sociedade, bem como ao planejamento de metas que estejam alinhadas com o desenvolvimento sustentável das organizaçôes. 
Neste contexto, uma empresa socialmente responsável tem como princípio o cumprimento de seus compromissos para com seus empregados, acionistas, parceiros e sociedade e busca através destas práticas exercer uma gestão ética, responsável e transparente em seus negócios. Cumprir com suas obrigaçóes perante o governo e atuando como agente de desenvolvimento sustentável, promovendo o desenvolvimento individual e coletivo nas regióes com as quais mantem vínculo (MELO; MELO, 2018).

Contudo, destaca-se que na sociedade organizacional são vários os fatores que impulsionam açóes e práticas de Responsabilidade Social. De acordo com Tenório (2015), pressóes externas como as legislaçôes, sindicatos e movimentos sociais cobram essas açóes por parte das empresas, assim como a influência de organizaçôes internacionais como a Organização Mundial do Comércio (OMC) e Organização das Naçóes Unidas (ONU) as quais incentivam empresas a optar por códigos de conduta e princípios ligados a preservação ambiental e respeito trabalhista.

No entanto, o que de fato leva essas empresas a optarem por uma postura mais responsável é a complexidade do ambiente de negócio, onde empresas são pressionadas a observarem quais são os impactos causados pelas atividades empresariais e qual o retorno oferecido a sociedade (TENÓRIO, 2015).

Observa-se que a sociedade está cada vez mais envolvida junto as ações e desenvolvimento de boas práticas empresariais. De acordo com o estudo desenvolvido pelo Instituto Akatu no ano de 2013, pesquisas indicam que o consumidor brasileiro possui informação sobre sustentabilidade e valoriza boas práticas de Responsabilidade Social Empresarial das organizaçôes. A pesquisa mostrou que consumidores valorizam principalmente seis práticas sustentáveis, sendo essas: Condiçōes dignas de trabalho, sem trabalho infantil ou escravo, diversidade e igualdade de oportunidade, remuneração justa, sem diferenciação de idade, gênero ou cor, bem-estar voltados ao consumidor salientando as medidas para minimizar os impactos das atividades, isonomia em relação ao trabalho terceirizado, bem como a eficiência no uso da água (INSTITUTO AKATU, 2013).

Neste cenário, segundo Laville (2002), as práticas de responsabilidade social contemplam a dimensão econômica através do impacto das organizaçôes no sistema econômico social, dimensão ambiental relacionada aos impactos das empresas nos sistemas naturais, promovendo açóes para minimizar danos ao sistema e meio ambiente, e dimensão social que abrange todo sistema social no qual a empresa possui suas operaçóes, contemplando seus colaboradores, fornecedores, consumidores e comunidade.

Contudo, vale ressaltar que uma empresa socialmente responsável deve possuir suas práticas perante a sociedade alinhadas com seu discurso social, bem como estar constantemente preocupada com o impacto de sua atividade na sociedade.

\subsection{Percepçóes Propostas por Carroll}

Na concepção de Archie B. Carroll (1979; 1991), a Responsabilidade Social Empresarial pode ser compreendida como a ampliação das atribuiçóes empresariais, além da tradicional finalidade econômica e cumprimento das obrigações legais pertinentes à organização (CARROLL, 1991).

Segundo as percepçóes de Carroll (1979), apresentadas em sua literatura denominada A ThreeDimensional Conceptual Modelof Corporate Performance, para que a Responsabilidade Social Empresarial 
seja aceita por um gestor de negócio, a mesma deve contemplar toda gama de responsabilidades da organização. Seguindo este contexto, Carroll apresenta as quatro perspectivas sobre responsabilidade social: responsabilidade econômica, legal, ética e filantrópica.

Essa concepção de responsabilidade social é descrita como uma pirâmide, tendo em sua base o principal objetivo das organizaçôes, a geração de lucro, representada pela responsabilidade econômica. Segundo Carroll $(1979 ; 1991)$, esta compõe a sua base devido ao histórico no qual as organizaçóes foram criadas como entidades economicamente projetadas para fornecer bens e serviços para os membros da sociedade e através deste processo fornecer um lucro aceitável, sem este componente não há legitimidade ou segurança.

Figura 1: Pirâmide de Responsabilidade Social Empresarial

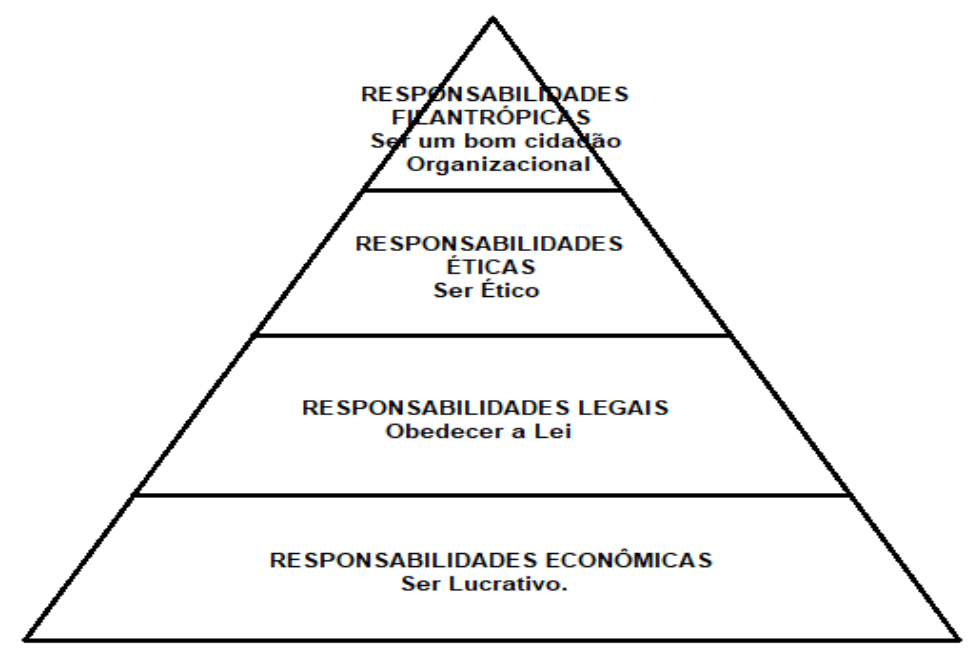

Fonte: Carroll (1991).

Outro viés importante se deu pelo estabelecimento do lucro ser o principal incentivo para o empreendedorismo, além da constante noção de maximizar os lucros, ideia presente até os dias atuais. Segundo Carroll $(1979 ; 1991)$, todas as outras responsabilidades comerciais têm como base a responsabilidade econômica da empresa, pois sem ela as demais tornam-se consideraçóes irrelevantes.

No segundo patamar da pirâmide fica a responsabilidade Legal, sendo essa a responsabilidade da organização em se portar em conformidade com as leis e regulamentos sob os quais a empresa deve operar. Segundo Carroll (1979; 1991), espera-se que as organizaçóes persigam seus anseios econômicas dentro das leis, as responsabilidades legais reflitam uma visão que incorporam noçóes básicas de que as operaçôes empresariais serão justas, conforme estabelecido pelas leis.

De acordo com Carroll $(1979$; 1991) no terceiro nível da pirâmide se encontram as responsabilidades éticas, as quais embora sejam incorporadas nas responsabilidades anteriores, abrangem outros aspectos os quais são esperados pela sociedade, embora não estejam em leis. A responsabilidade ética incorpora normas e expectativas que refletem uma preocupação no qual os consumidores, funcionários, acionistas e a comunidade consideram justo, de acordo ou em respeito aos direitos morais das partes interessadas, como princípios de justiça, direito e utilitarismo. Segundo Carroll (1979; 1991), essa responsabilidade incorpora valores emergentes e normas que a sociedade espera que as organizaçóes adotem, embora, tais valores possam refletir maior padrão de desempenho que o atual requerido em lei. 
No quarto e último patamar da pirâmide encontram-se as responsabilidades filantrópicas, essa responsabilidade engloba as açôes e atitudes corporativas das organizaçôes em ser boas cidadãs corporativas (Carroll, 1979; 1991). Essas atitudes segundo o autor descrevem a participação ativa das empresas em se envolver em programas que promovam o bem-estar da sociedade, seja por contribuiçóes comerciais, recursos financeiros, contribuição para comunidade, educação, disponibilização de instalações e funcionários para desenvolvimento de programas humanitários. Essa responsabilidade conforme Carroll (1979; 1991) é discricionária ou voluntária por parte da empresa, pois embora haja uma expectativa da sociedade que as organizaçóes atendam a esse anseio, caso não haja tal fornecimento em nível desejado pela sociedade, não haverá um entendimento dessas empresas como antiéticas.

\subsection{Estudos Relacionados}

Estudos relacionados às percepçóes de Carroll (1979; 1991) serviram de base para diversas pesquisas relacionadas a RSE. O estudo desenvolvido por Macêdo e Cândido (2011) objetivou identificar as percepçôes dos stakeholders acerca das açóes de responsabilidade social adotadas por uma empresa têxtil do estado da Paraíba, utilizando o modelo tridimensional de Carroll (1979; 1991). Para a análise efetivouse um estudo de caso e foram construídos roteiros de entrevistas baseados no modelo abordado. Ao final do estudo os resultados indicaram que os agentes internos possuem uma opiniáo mais favorável em relação à empresa do que os agentes externos, sendo a concepção dos agentes externos baseada em nível de conhecimento sobre o conceito de responsabilidade social. Desta forma concluiu-se com a pesquisa que a empresa precisa criar iniciativas mais abrangentes que estimulem maior interação e gerem conhecimento aos seus stakeholders.

O estudo desenvolvido por Tozzo, Igarashi et al. (2017) que serviu de base para este estudo tinha como objetivo verificar quais das percepçóes propostas por Carroll $(1979$; 1991) foram explicitadas pelas empresas do setor de energia elétrica, e em qual se realizaram os maiores investimentos financeiros. A pesquisa foi realizada nas três empresas com melhor classificação no ranking das 500 maiores em vendas da Revista Exame de 2015, tendo como base para análise dos dados os exercícios de 2007 e 2015. Foram selecionados para análise as empresas, Cemig GT (MG), Tractebel (SC), e a AES Tietê (SP) ambas de capital aberto. Ao final da pesquisa foi observado que a perspectiva que mais incide sobre as práticas sociais é a ética, seguida pela perspectiva filantrópica, econômica e legal. Destaca-se ainda que cada companhia apresentou prioridades diferentes quando ao direcionamento de açóes, observando que a Cemig GT realizou maiores açóes com objetivos socias, Tractebel em açóes ligadas ao meio ambiente e a AES Tietê apresentou equilíbrio entre as açôes ambientais e público interno. Quando ao direcionamento financeiro a perspectiva ética recebeu maiores investimentos, seguidos pela filantrópica, econômica e legal.

Appio, Madruga e Frizon (2018) realizaram um estudo objetivando analisar as dimensóes de RSE na concepçáo piramidal proposta por Carroll, a partir da percepção dos stakeholders de uma empresa prestadora de serviço contábil do Sudoeste do Paraná. Para a análise foram respondidos questionários fechados com escala numérica, aplicado aos stakeholders e colaboradores da empresa, além de uma amostra de 95 clientes. Ao final da pesquisa constatou-se que a dimensão econômica foi a mais visível na percepção dos clientes e colaboradores, seguida das dimensóes ética, legal e discricionária. Em relação 
aos stakeholders constatou que a empresa possui atuação predominante no campo da responsabilidade econômica evidenciando que as açóes são voltadas a maximização dos lucros.

\section{Procedimentos Metodológicos}

A pesquisa classifica-se como descritiva, pois através da análise dos relatórios busca descrever quais foram as açóes de responsabilidade social desenvolvidas pela empresa, e em quais delas é possível evidenciar as percepções de RSE apresentadas por Carroll.

A coleta de dados foi realizada através da análise documental dos relatórios anuais administrativos e socioambientais da empresa Petróleo Brasileiro S.A. Segundo Manini (2002), o documento "é a concretização de toda informação registrada (e útil, para ser guardada) - independente de qual seja o suporte desta informação - passível de transmitir conhecimento; é o testemunho da realização da atividade humana”.

A pesquisa documental é aquela em que os dados obtidos são estritamente provenientes de documentos, com o objetivo de extrair informaçóes neles contidas, a fim de compreender um fenômeno; é um procedimento que se utiliza de métodos e técnicas para a apreensão, compreensão e análise de documentos dos mais variados tipos (FLICK, 2008).

Se classifica como um estudo de caso, o qual é caracterizado pelo estudo profundo de um ou poucos objetos, o que permite amplo conhecimento e detalhamento sobre o objeto pesquisado (GIL, 2008). A população do estudo é a empresa Petróleo Brasileiro S.A (Petrobrás), maior empresa de exploração de petróleo do país, cuja sede fica situada na cidade do Rio de Janeiro - RJ, atualmente conta com 15 refinarias instaladas em 10 estados brasileiros e 10 bacias de exploração. Compóem a amostra do estudo os relatórios anuais administrativos e de sustentabilidade dos anos de 2016, 2017 e 2018.

Para o atendimento do objetivo proposto nesta pesquisa, os relatórios anuais e de sustentabilidade foram coletados diretamente do website da companhia, e mediante a leitura, foram interpretados e tabulados em planilha eletrônica de acordo com a finalidade do projeto ou ação desenvolvida, bem como o seu direcionamento de acordo com as percepçóes propostas por Carroll.

Para a atribuição das açóes em cada uma das percepçóes propostas pelo autor, foi necessário a interpretação de cada uma das variáveis descritas nos relatórios, buscando identificar se para a realização da ação proposta foram investidos recursos financeiros, disponibilização de colaboradores e materiais, se a mesma estava amparada por alguma norma ou lei, bem como se essas atendiam a algum anseio da sociedade, seja através de açôes voltadas a comunidade ou aos colaboradores. Após está primeira etapa, efetuou-se a análise vertical com a finalidade de identificar o percentual de açóes desenvolvidas em cada perspectiva e análise horizontal para identificar a variação na quantidade de açóes desenvolvidas nos anos analisados. 


\section{Análise de Dados}

$\mathrm{Na}$ seção 4 da pesquisa, foram apresentadas as açôes de responsabilidade social desenvolvidas pela empresa Petróleo Brasileiro S.A, considerando os anos de 2016 a 2018, extraídas dos relatórios anuais e de sustentabilidade divulgados.

\subsection{Açóes Desenvolvidas em 2016}

A partir da coleta e análise dos relatórios anual e de sustentabilidade no ano de 2016, foi possível identificar que a companhia desenvolveu nove açóes de RSE e 100\% das açóes se enquadraram na perspectiva ética, $67 \%$ das açôes contemplaram a perspectiva econômica, 55\% apresentaram aspectos legais e em 55\% observou-se características filantrópicas.

Figura 2: Percentual por ação em 2016

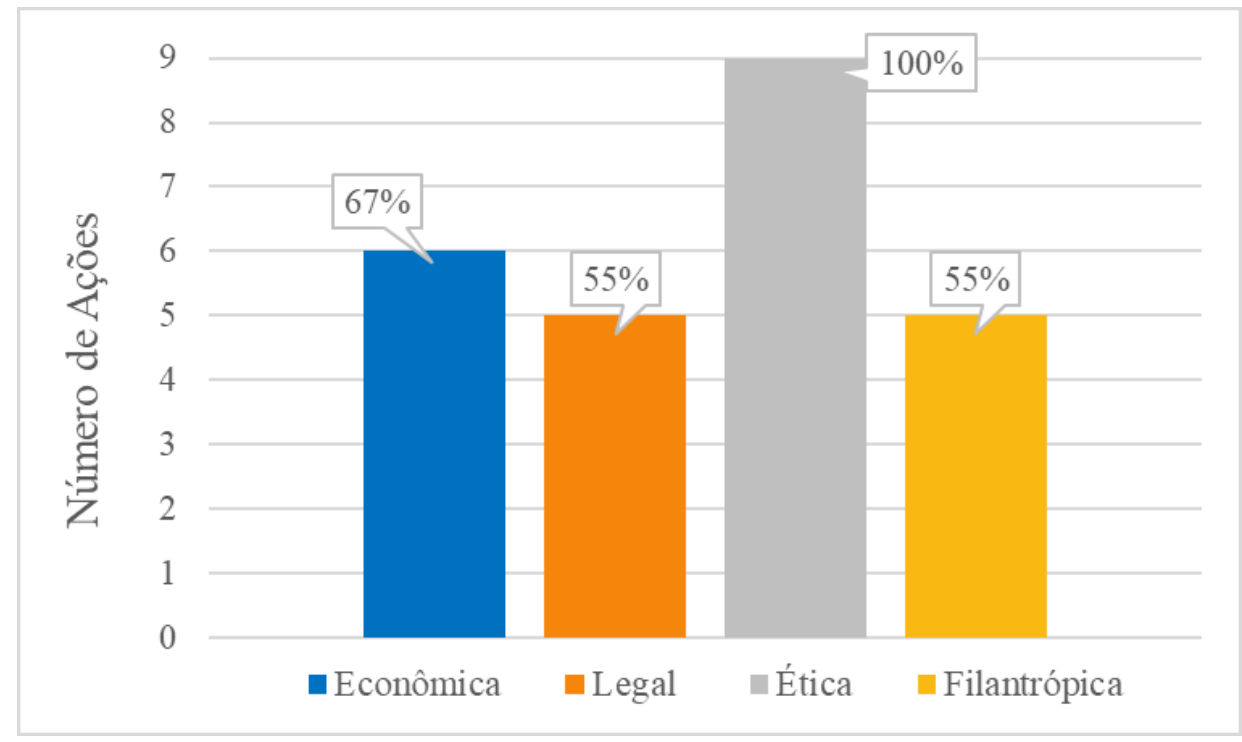

Fonte: Elaborado pelos autores a partir dos resultados (2019)

Dessas açóes, três contemplaram 100\% da Teoria proposta por Carroll (1979; 1991), sendo o Programa Petrobrás Socioambiental, cumprindo com o caráter econômico através do investimento de $\mathrm{R} \$ 120$ milhóes ligados a 470 iniciativas de projetos socioambientais, que engloba parceria com mais de 700 entidades, o caráter legal foi cumprido através da conservação de áreas naturais, bem como por estar em conformidade com a Lei n ${ }^{\circ} 9.605$ (BRASIL, 1998), Lei dos Crimes Ambientais, Lei n 6.938 (BRASIL, 1981) a qual Institui a Política e o Sistema Nacional do Meio Ambiente e ISO 14.001 de Gestão Ambiental (ABNT, 2015).

A perspectiva ética e filantrópica foram atendidas, pois através destas açóes amplia sua atuação junto à comunidade, governo e universidades, contribuindo para a mitigação dos riscos socioambientais relacionados a companhia, atuando como parceira de projetos de incentivo educacional, Fundaçáo ProTamar, Instituto Baleia Jubarte, além da contribuição para realização de estudos e projeto de conservação 
da biodiversidade marinha. Em 2016, o programa patrocinou 16 projetos de conservação de áreas naturais, recuperação e reconversão de áreas degradadas.

Contemplando as quatro perspectivas, encontram-se também os Programas de Incentivo à Cultura e Esporte, que destacou um investimento financeiro de $\mathrm{R} \$ 71$ milhóes destinados a projetos que patrocinam cerca de 196 açóes culturais, e R $\$ 50$ milhóes destinados a 16 projetos esportivos, cumprindo através desses investimentos a perspectiva econômica.

Quanto a legalidade desses programas se verificou o cumprimento e conformidade com a Lei $\mathrm{n}^{\circ}$ 8.313 (BRASIL, 1991), mais conhecida como Lei Rouanet que institui o Programa Nacional de Apoio à Cultura, e Lei $n^{\circ} 11.438$ (BRASIL, 2006) que dispóe sobre os incentivos e benefícios destinados a fomentar as atividades esportivas. Em ambos os projetos, a companhia além de ganhar grande visibilidade junto a sociedade recebe benefícios fiscais através dos incentivos destinados aos mesmos.

$\mathrm{Na}$ relação com perspectiva ética e filantrópica destaca-se o cumprimento pelo objetivo dos programas que é levar e possibilitar o acesso a projetos de cultura e esporte a toda sociedade, seja através da música, artes cênicas, literatura ou através do patrocínio a jovens promessas do esporte e atletas consagrados, democratizando o acesso cultura pela realização de eventos gratuitos ou a preços populares.

Com relação ao Programa de Pesquisa, Desenvolvimento e Inovação, observou-se a concordância com três perspectivas sendo a econômica, ética e filantrópica. A característica econômica pode ser identificada pelo investimento de $\mathrm{R}$ \$ 1.826 milhóes para realização de pesquisas e o seu desenvolvimento, quanto ao aspecto ético e filantrópico, o programa atua em parceria com universidades, instituiçôes de pesquisa e desenvolvimento de estudos que buscam reduzir os riscos inerentes a atividade, além do desenvolvimento de açôes que visam atender as comunidades no qual a companhia possui instalaçóes, patrocinando a formação de agentes comunitários.

Relacionados a perspectiva econômica e ética observou-se duas açôes, o Programa de Controle Médico de Saúde Ocupacional, sendo identificado um investimento destinado a saúde, segurança e meio ambiente que totalizou $\mathrm{R} \$ 5,88$ bilhóes com destinação ao programa de promoçáo a saúde de funcionários, o qual promove o desenvolvimento de estímulos a vida ativa, prevenção e controle dos fatores de risco e doenças, avaliação médica e odontológica. Quanto a perspectiva ética a companhia desenvolve dentro deste programa açóes vinculadas ao tratamento de problemas relacionados ao uso de álcool e outras drogas, promovendo açôes de prevenção e educação aos funcionários, além de disponibilizar o tratamento e acompanhamento para as famílias.

O outro programa refere-se ao Desenvolvimento de Recursos Humanos o qual atua diretamente no treinamento e capacitação dos funcionários. A perspectiva econômica foi atendida pelo investimento de 76 milhôes destinados a realização das capacitações diretamente nas unidades e uso de maior tecnologia educacional. Com relação a perspectiva ética, a mesma foi atendida pelo registro de 249 mil participaçóes em cursos de capacitaçáo de empregados, o que confirma o compromisso da companhia com o desenvolvimento do quadro de funcionários, fornecendo treinamento que buscam o desenvolvimento desses junto a companhia, além de iniciativas que visam a prevenção de novos acidentes e combate à corrupção no sistema.

A companhia realizou no ano de 2016 dois programas que cumpriram aspecto da perspectiva ética e legal, o primeiro foi o Programa Compromisso com a Vida, que tem como objetivo aprimorar a 
consciência de segurança na companhia e comprometimento das lideranças na formação continua sobre os riscos. A perspectiva legal foi atendida por estar em conformidade com os direitos previstos no Art. $7^{\circ}$ da Constituição de 1988, o qual prevê a redução dos riscos inerentes ao trabalho, OHSAS 18.001 de gestão de saúde e segurança, além da criação das Regras de Ouro, um conjunto de dez açôes destinadas ao fortalecimento e cultura de segurança na companhia. O caráter ético pode ser identificado pelo esforço em reduzir a taxa de acidentados registráveis - TAR de 2,2 em 2015 para 1,4 até 2018 reforçando os aspectos comportamentais de segurança dos trabalhadores e o número de acidentes que causam derramamento de petróleo e derivados no meio ambiente.

Já o Programa Petrobrás de Prevenção da Corrupção possui iniciativas de compliance, em consonância com às legislações anticorrupção, como a Lei no 12.846 (BRASIL, 2013) mais conhecida como Lei Anticorrupção que dispóe sobre a responsabilização de pessoas jurídicas pelas práticas e atos contra a administração, e Foreign Corrupt Practices Act, lei estadunidense anticorrupção no exterior, além de seguir um conjunto de padróes e regulamentos internos para o combate a corrupção, atendendo assim a perspectiva legal e ética da teoria de Carroll (1979; 1991).

A companhia também possui o Programa de Responsabilidade Social o qual atendeu a perspectiva ética e filantrópica, caráter atendido por respeitar direitos humanos, buscando prevenir impactos negativos e fortalecendo a relação com as comunidades, através do programa denominado Agenda 21, que fomentou à elaboração de ações em 193 comunidades vizinhas as unidades operacionais, promovendo plano com foco em saúde, segurança pública, emprego e educação, capacitando cerca de 4,4 mil pessoas em gestão social e comunicação comunitária.

\subsection{Açôes Desenvolvidas em 2017}

No ano de 2017 através da tabulação das ações e projetos explicitados nos relatórios da companhia, foi possível identificar o direcionamento de nove açôes de responsabilidade social de acordo com as percepçôes proposta por Carroll $(1979 ; 1991)$. Dessas 100\% contemplaram a concepçáo ética, em $78 \%$ das açóes foi possível identificar o caráter legal, 67\% apresentaram direcionamento econômico e a perspectiva filantrópica identificada em $55 \%$ dos projetos.

Figura 3: Percentual por ação em 2017

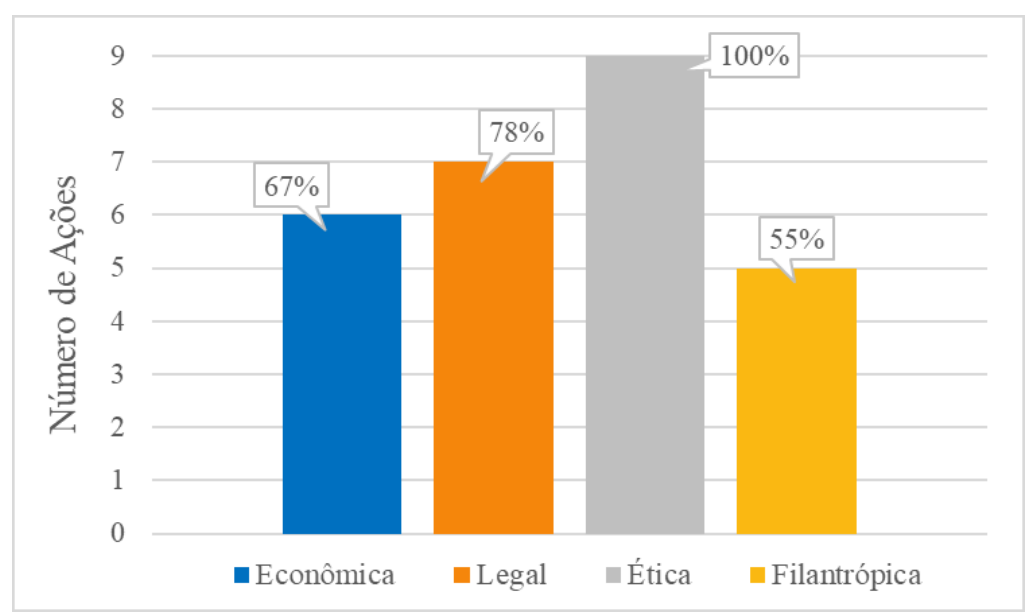

Fonte: Elaborado pelos autores a partir dos resultados (2019) 
Com relação ao cumprimento de $100 \%$ da Teoria de Carroll, observou-se quatro açôes, o Programa Petrobrás Cultural que recebeu um investimento de R \$ 61 milhóes atendendo a perspectiva econômica. Para o ano de 2017 o programa passou a patrocinar as linhas audiovisual, música e artes cênicas, os quais possuem maior visibilidade e trazem maior retorno a marca, promovendo o lançamento do Prêmio Petrobrás de Cinema, apresentação em diversas cidades do espetáculos do Grupo Galpão e apresentações musicais pela Orquestra Petrobrás Sinfônica, além da realização de diversos projetos apoiados pelo programa, proporcionando o acesso à cultura e entretenimento a diversas regióes do país, cumprindo desta forma a perspectiva ética e filantrópica, além de estar em conformidade com a lei de incentivo à cultura.

Relacionado as quatro perspectivas destaca-se o Programa Petrobrás Esportivo, projeto que seguiu as mesmas diretrizes do ano anterior promovendo a realização de maratonas, esporte educacional, formação de professores e atuação de diversos profissionais na gestão e condução de projetos ligados ao programa, cumprindo desta forma a perspectiva ética e filantrópica, além da legalidade do programa por estar de acordo com a lei de incentivo ao fomento de atividades esportivas e investimento de $\mathrm{R} \$ 21$ milhóes, cumprindo desta forma com a perspectiva econômica.

$\mathrm{Na}$ linha ambiental relacionado com as quatro perspectivas foram desenvolvidas duas açóes, o Programa de Gestão de Recursos Hídricos, projeto realizado em parceria com empresas, instituições de pesquisa e universidades, e tem seu direcionamento voltado a garantir o fornecimento de água necessária para a operacionalização da companhia, bem como por otimizar o uso dos recursos hídricos e avanço nas pesquisas de dessalinização de água, para esse programa foram destinados $\mathrm{R} \$ 14$ milhóes atendendo a perspectiva econômica.

O projeto abrange a perspectiva legal, pois está em concordância com a Lei $n^{\circ} 9.433$ (BRASIL, 1997) conhecida como Lei das Águas a qual instituiu a Política Nacional de Recursos Hídricos. Quanto as perspectivas ética e filantrópica, a mesma foi cumprida pelo objetivo do projeto que busca a proteção de nascentes, gestão de recursos hídricos, racionalização no uso da água, diminuição na captação de "água nova" substituindo pela água dessalinizada e açôes de reuso.

O segundo projeto trata-se do Programa Petrobrás Socioambiental, onde foi investido R \$ 60 milhôes, o programa atua no fortalecimento da companhia junto as comunidades, instituiçóes do terceiro setor, poder público e universidades, contribuindo para a preservação do meio ambiente e melhoria na condição de vida das comunidades.

A legalidade do programa está vinculada diretamente com a Política de Responsabilidade Social da Petrobrás e em conformidade com a Lei Ambiental. Quanto a perspectiva ética e filantrópica, se enquadra pelos projetos apoiados pelo programa, como o Projeto Semeando Água que tem por objetivo reverter a degradação dos corpos hídricos na região do Sistema Cantareira. Destaca-se também os projetos que atuam diretamente na conservação do meio ambiente e territórios de povos indígenas, contemplando 19 projetos que beneficiam diretamente 20 comunidades indígenas, promovendo atividades de desenvolvimento de produtos florestais (não madeireiros) como látex, artesanatos e capacitação de indígenas, além do desenvolvimento de projetos comunitário.

Relacionado com as perspectivas econômica, ética e filantrópica foi desenvolvido o Programa de Pesquisa, Desenvolvimento e Inovação, que seguindo os parâmetros do ano anterior e cumprindo com a 
perspectiva ética e filantrópica, contou com a colaboração de 193 universidades e institutos de pesquisas, além da parceria com comunidade científica e acadêmica para o desenvolvimento de tecnologias que visam atender o melhoramento no processo operacional e segurança das comunidades, contando com um investimento de $\mathrm{R} \$ 1.831$ milhóes no ano de 2017.

Atendendo a perspectiva legal e ética a companhia desenvolveu três ações, o Programa de Gestão de Resíduos que atende ao disposto na Lei n ${ }^{\circ} 12.305$ (BRASIL, 2010) que institui a Política Nacional de Resíduos Sólidos e NBR 10.004 (ABNT, 2004). O programa busca minimizar os impactos causados pelo descarte de resíduos gerados pela operacionalização da companhia, adotando procedimentos de redução da geração de resíduos na origem, coleta seletiva para separação em resíduos sólidos perigosos e não perigosos, tratamento e acomodação final dos resíduos, visando diminuir os impactos ao meio ambiente e sociedade.

Os outros dois programas são o Programa Petrobrás de Prevenção da Corrupção que conforme apresentado no ano de 2016 segue priorizando a conformidade com a legislação anticorrupçáo e regulamentos internos para o combateà fraude, lavagem de dinheiro e corrupção, estabelecendo mecanismos de prevenção, detecção e correção de atos divergentes as condutas estabelecidas, bem como por avaliar os riscos inerentes aos relacionamentos comerciais e de transparência na condução da companhia.

O Programa Compromisso com a Vida, o qual visa criar açóes preventivas e tratamentos de desvios e incidentes, com o objetivo de fortalecer as diretrizes de segurança em todas as etapas dos processos operacionais, sendo alinhado através deste programa a nova Política de Segurança, Meio Ambiente e Saúde ampliando o compromisso assumido com o cuidado com a vida e meio ambiente. Uma das iniciativas do programa no ano de 2017 refere-se ao treinamento em segurança operacional de 185 mil pessoas e realização do Congresso de SMS com o objetivo de divulgar as boas práticas de segurança, meio ambiente e saúde, contemplando a perspectiva ética e legal do programa.

Por fim, relacionado à perspectiva econômica e ética está o Programa de Desenvolvimento de Recursos Humanos, que recebeu um investimento de R \$33,15 milhóes na capacitaçáo dos empregados, visando o aprimoramento da capacidade de análise crítica e inovação, buscando o aperfeiçoamento na realização das atividades e autodesenvolvimento.

\subsection{Açóes Desenvolvidas em 2018}

Através das análises dos relatórios no ano de 2018 foram identificadas dez açóes em conformidades com as perspectivas de responsabilidade social proposta por Carroll (1979; 1991). Dentre as açóes apresentadas nos relatórios observou-se que, em 90\% das açóes cumpriu-se a perspectiva ética, 70\% cumpriu com os aspectos econômico e legal, bem como 50\% estavam ligadas a perspectiva filantrópica. 
Figura 4: Percentual por ação em 2018

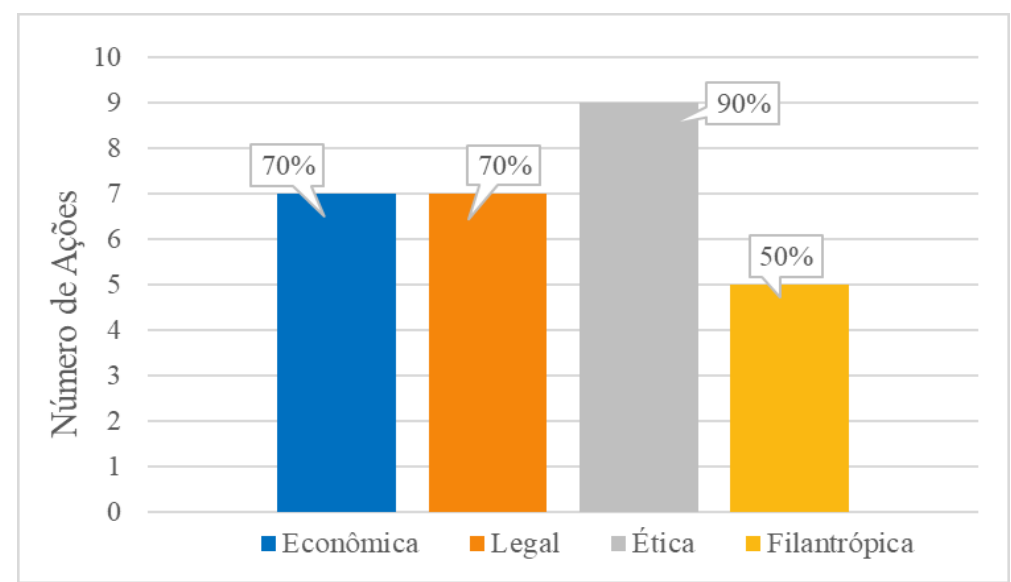

Fonte: Elaborado pelos autores a partir dos resultados (2019)

Relacionado com as quatro perspectivas da teoria de Carroll foram desenvolvidos quatro programas, sendo eles o Programa de Gestáo de Recursos Hídricos, projeto desenvolvido no ano de 2017, e que esteve presente no ano de 2018 dando continuidade à elaboraçáo de pesquisas relacionadas ao gerenciamento de recursos hídricos, recebendo um investimento total de R \$ 22 milhóes, utilizados entre outras finalidades para o aprimoramento e gestáo do sistema de resfriamento, tratamento de efluentes e gestão de recursos.

O caráter legal do programa foi cumprido por estar em conformidade com as leis aplicáveis ao uso e gerenciamento de recursos hídricos, além da racionalização da água utilizada na operacionalização da companhia. Quanto a perspectiva ética e filantrópica é atendida pela parceria do programa com instituiçóes de pesquisas e universidades, ampliando a importância do tema junto à comunidade acadêmica. Destacase ainda que foram reutilizados aproximadamente 84 milhôes de $\mathrm{m}^{3}$ de água em 2018 gerando uma economia no custo de captação e no lançamento de efluentes de $\mathrm{R}$ \$28,6 milhóes.

$\mathrm{Na}$ linha de desenvolvimento de cultura e esporte, foram apresentados dois projetos, o Programa Petrobrás Cultural e Programa Petrobrás Esportivo. A adesão da perspectiva econômica foi atendida pelo investimento de $\mathrm{R}$ \$ 118 milhóes revertido aos projetos, sendo destinado $\mathrm{R}$ \$ 38,3 milhóes a iniciativas culturais e R \$ 79,7 milhôes a projetos esportivos. A legalidade dos programas está relacionada ao incentivo e desenvolvimento de cultura e esporte, através do patrocínio e democratizaçáo do acesso.

Quanto a perspectiva ética e filantrópica, observou-se através do patrocínio a festivais de cinema, projeto Sessão Vitrine que exibe filmes nacionais em mais de 20 cidades brasileiras com entrada a valor reduzido, manutençáo de companhias de teatro e dança que promovem a capacitaçáo e ensino de crianças e jovens em áreas culturais. Referente aos projetos esportivos destaca-se o patrocínio ao esporte motor e de rendimento, através do relançamento do Time Petrobrás o qual atende a preparação de atletas de alta performance para a participaçáo em jogos olímpicos e projetos comunitários de incentivo ao esporte.

Por fim na linha socioambiental destaca-se o Programa Petrobrás Socioambiental o qual recebeu um investimento de $\mathrm{R} \$ 87$ milhóes cumprindo com a perspectiva econômica, no ano de 2018 foram fortalecidos cerca de 100 projetos socioambientais em 20 estados. Com relação a perspectiva ética e filantrópica, essas foram atendidas através do beneficiamento de aproximadamente 85 mil pessoas por 
meio de educação complementar, educação ambiental e formação de professores, atendendo cerca de 50 mil crianças em atividades educacionais.

$\mathrm{Na}$ dimensão ambiental foram apoiados 43 projetos ligados a conservação de espécies em extinção, 28 projetos de beneficiamento a comunidades tradicionais, além de açôes voltadas a desenvolvimento de educaçáo ambiental em escolas e comunidades de pescadores com foco na biodiversidade marinha. Ligado ao programa foram criadas açôes voluntárias como o projeto Viveiro Cidadáo que estimula a implementação de sistemas produtivos, projeto Trilha Empreendedora atendendo 2,3 mil alunos com programas de empreendedorismo e educação financeira. A parte social do programa é contemplada, através de cerca de 6 projetos que atuam na realização de atividades de sustentabilidade e envolvimento de funcionários e público em geral em atividades de limpeza de praias e campanhas de doação.

Cumprindo com a perspectiva econômica, ética e filantrópica encontra-se o Programa de Pesquisa, Desenvolvimento e Inovação o qual através de parcerias com a comunidade e universidades está voltado ao desenvolvimento de tecnologia que contribua para o crescimento sustentável da companhia, agregando valor ao capital intelectual e contribuindo para o desenvolvimento das comunidades e da sociedade. No ano de 2018 foram investido $\mathrm{R} \$ 2.349$ milhóes para a criaçáo de novas pesquisas e continuidade de projetos voltados ao avanço tecnológico.

Atendendo a perspectiva legal e ética destacam-se três ações, o Programa de Gestão de Resíduos, que visa a destinação correta dos resíduos gerados pela operacionalização da companhia, mitigando impactos gerados no meio ambiente e evitando a contaminação do solo, bem como por atender a lei aplicável ao gerenciamento de resíduos.

O Programa Compromisso com a Vida, projeto realizado desde 2016, sendo apontado o cumprimento do objetivo de reduzir a TAR - taxa de acidentados registráveis, passando de 2,15 em 2015 para 1,01 em 2018, uma redução de 47\%. Em 2018 foram realizados treinamentos vinculados ao programa compromisso com a vida que atenderam mais de 18.500 pessoas, fortalecendo a cultura de segurança junto aos funcionários e fornecedores.

Ligado a perspectiva ética e legal, o Programa Petrobrás de Prevenção da Corrupção, vigente desde 2013 e em conformidade com as leis nacionais e internacionais de combate a crimes de corrupção. No ano de 2018 com o objetivo de aprimorar a continuidade das açóes foi revisada a Política de Compliance, aprovada pela alta administração, tornando essa mais acessível e fortalecendo temas com relação a prevenção, além da realizar Due Diligence de Integridade (DDI) visando conhecer e avaliar os riscos de integridade relativo ao relacionamento com fornecedores, clientes e instituiçóes em projetos de patrocínios.

Durante o exercício de 2018, assim como nos anos anteriores, foi desenvolvido o Programa de Desenvolvimento de Recursos Humanos, o qual vinculado a perspectiva econômica, teve um investimento de R \$ 112,4 milhóes, destinado a capacitação dos funcionários, programa de capacitação corporativa e Universidade Petrobrás, além do atendimento a perspectiva ética através da trilha de desenvolvimento individual, que proporciona ao funcionário a participação em cursos de formação visando a manutenção e crescimento da capacidade técnica da companhia. Em 2018 foram registradas 266,7 mil participaçôes em cursos de formação de novos funcionários e educação continuada, gerando uma média de 53 horas de treinamento por empregado. 
Destaca-se ainda um projeto vinculado a perspectiva econômica, nesse observou-se a destinação de R\$ 14,9 milhóes para a realização de Eventos de Negócios, Ciência e Tecnologia, porém não foram encontradas informaçôes referentes ao projeto, somente a divulgação do investimento para a realizaçáo dos eventos, desta forma sendo este vinculado somente a perspectiva econômica.

\subsection{Descrição dos Resultados referente aos três anos analisados}

Através das análises dos relatórios administrativos e de sustentabilidade, dos anos de 2016 a 2018, observou-se que em todos os anos analisados foi possível verificar que ao menos três açóes contemplaram as quatro perspectivas propostas por Carroll, sendo que em todos os anos a perspectiva ética obteve maior evidenciação entre as ações e projetos apresentados pela companhia.

Tabela 1: Resumo das Perspectivas de RSE

\begin{tabular}{|c|c|c|c|c|c|c|c|c|c|c|c|c|}
\hline \multirow{3}{*}{ Ações Desenvolvidas } & \multicolumn{12}{|c|}{ Perspectivas de RSE } \\
\hline & \multicolumn{3}{|c|}{ Econômica } & \multicolumn{3}{|c|}{ Legal } & \multicolumn{3}{|c|}{ Ética } & \multicolumn{3}{|c|}{ Filantrópica } \\
\hline & 2016 & 2017 & 2018 & 2016 & 2017 & 2018 & 2016 & 2017 & 2018 & 2016 & 2017 & 2018 \\
\hline Programa Petrobras Cultural & $\mathrm{x}$ & $x$ & $\mathrm{x}$ & $x$ & $x$ & $\mathrm{x}$ & $\mathrm{x}$ & $\mathrm{x}$ & $x$ & $\mathrm{x}$ & $\mathrm{x}$ & $x$ \\
\hline Programa Petrobras Esportivo & $\mathrm{x}$ & $x$ & $\mathrm{x}$ & $x$ & $x$ & $x$ & $\mathrm{x}$ & $x$ & $x$ & $\mathrm{x}$ & $x$ & $x$ \\
\hline Programa Petrobras Socioambiental & $\mathrm{x}$ & $\mathrm{x}$ & $x$ & $x$ & $\mathrm{x}$ & $\mathrm{x}$ & $\mathrm{x}$ & $\mathrm{x}$ & $\mathrm{x}$ & $\mathrm{x}$ & $x$ & $x$ \\
\hline Programa de Pesquisa, Desenvolvimento e Inovação & $\mathrm{x}$ & $\mathrm{x}$ & $\mathrm{x}$ & & & & $\mathrm{x}$ & $\mathrm{x}$ & $\mathrm{x}$ & $\mathrm{x}$ & $\mathrm{x}$ & $x$ \\
\hline Programa de Controle Médico de Saúde Ocupacional & $\mathrm{x}$ & & & & & & $\mathrm{x}$ & & & & & \\
\hline Programa de Desenvolvimento de Recursos Humanos & $\mathrm{x}$ & $x$ & $x$ & & & & $x$ & $x$ & $x$ & & & \\
\hline Programa Compromisso com a Vida & & & & $x$ & $\mathrm{x}$ & $x$ & $\mathrm{x}$ & $x$ & $x$ & & & \\
\hline Programa de Prevenção da Corrupção & & & & $x$ & $\mathrm{x}$ & $\mathrm{x}$ & $\mathrm{x}$ & $\mathrm{x}$ & $\mathrm{x}$ & & & \\
\hline Programa de Responsabilidade Social & & & & & & & $\mathrm{x}$ & & & $\mathrm{x}$ & & \\
\hline Programa de Gestão de Recursos Hídricos & & $x$ & $\mathrm{x}$ & & $x$ & $x$ & & $\mathrm{x}$ & $x$ & & $\mathrm{x}$ & $x$ \\
\hline Programa de Gestão de Resíduos Sólidos & & & & & $x$ & $x$ & & $x$ & $x$ & & & \\
\hline Eventos de Negócios, Ciência e Tecnologia & & & $x$ & & & & & & & & & \\
\hline Percentual por Perspectiva & $67 \%$ & $67 \%$ & $70 \%$ & $55 \%$ & $78 \%$ & $70 \%$ & $100 \%$ & $100 \%$ & $90 \%$ & $\mathbf{5 5} \%$ & $\mathbf{5 5} \%$ & $50 \%$ \\
\hline
\end{tabular}

Fonte: Conforme dados da pesquisa

Para o direcionamento das açóes junto as percepçôes propostas por Carroll $(1979 ; 1991)$ foram consideradas algumas variáveis que as relacionavam com as quatro perspectivas. Sendo que na perspectiva econômica buscou-se identificar o valor financeiro vinculado ao desenvolvimento do projeto descrito no relatório. $\mathrm{Na}$ perspectiva legal verificou-se se a açáo realizada estava em conformidade com leis ou regulamentos vinculados à atividade da empresa, leis trabalhistas e ambientais.

Com relação a perspectiva ética buscou-se identificar se as açôes atenderam aos aspectos esperados pela sociedade, como a preocupação com a segurança e desenvolvimento dos funcionários, uso consciente dos recursos naturais, meio ambiente e a sua preservação. As variáveis analisadas junto a perspectiva filantrópica, referem-se as açóes que trazem contribuição a sociedade, através de açóes comunitárias, projetos educacionais e programas que contribuem para o desenvolvimento e bem-estar da sociedade. 
No geral, identificou-se que o percentual médio apresentado em cada ano não obteve grande variação, mantendo uma média de $97 \%$ de açóes com perspectiva ética, $68 \%$ nas açóes com direcionamento econômico e legal, e 53\% em açóes que atenderam a perspectiva filantrópica.

Com relação à pesquisa desenvolvida por Tozzo, Igarashi et al. (2017), artigo base utilizado para o desenvolvimento desta pesquisa, observou-se que assim como nas companhias analisadas no estudo anterior, a perspectiva ética foi a que obteve a maior evidenciação nos projetos desenvolvidos pela empresa Petróleo Brasileiro S.A, visto que em dois anos essa perspectiva esteve presente em 100\% das açóes. Referente a perspectiva filantrópica, a mesma obteve a menor evidenciação por ação apresentada neste estudo, divergindo dos dados apresentados no estudo base, no qual a perspectiva filantrópica foi a segunda em evidenciação nas açóes das companhias analisadas. Cabe ressaltar que neste estudo foram analisados os relatórios anuais e de sustentabilidade de todos os anos da pesquisa (2016 a 2018), o que pode ter ocasionado essa maior discrepância entre os dados, visto que no estudo base os resultados foram coletados somente nos relatórios de sustentabilidade.

O resultado da pesquisa difere dos resultados encontrados pelos pesquisadores Appio, Madruga e Frizon (2018) os quais identificaram que a perspectiva que obteve maior evidenciação, refere-se a perspectiva econômica, seguido do aspecto ético, legal e filantrópica.

\section{Considerações Finais}

O debate sobre o tema Responsabilidade Social está cada vez mais presente no mundo organizacional, as primeiras discussóes sobre RSE tiveram início em meados de 1960 em países da Europa e nos Estados Unidos, através de movimentos sociais que defendiam uma postura mais ampla de atuação social por parte das organizaçóes. Esses movimentos trouxeram um olhar mais equilibrado entre a geração de lucro para os acionistas e as açóes desenvolvidas em prol da sociedade e meio ambiente.

Neste contexto, segundo Archie B. Carroll (1979; 1991), a Responsabilidade Social Empresarial está além da tradicional finalidade econômica e legal das empresas, descrevendo que essas devem atender aos anseios por parte da sociedade. Em sua literatura são apresentadas as quatro perspectivas de responsabilidade social, contemplando a perspectiva econômica, legal, ética e filantrópica. A partir das percepções de RSE descritas por Carroll, este estudo teve como objetivo apresentar em quais açôes desenvolvidas pela empresa Petróleo Brasileiro S.A é possível evidenciar as percepçôes de Responsabilidade Social Empresarial.

Com base nos resultados da pesquisa observou-se que, em todos os anos analisados foram desenvolvidos programas que tiveram ao menos uma iniciativa em conformidade percepçóes de RSE, destacando que em todos os anos a perspectiva ética foi apontada como o principal aspecto cumprido nas açóes apresentadas pela companhia. Em síntese nos três anos que serviram de base para a pesquisa constatou a realização de 28 açóes/programas, sendo que 2016 e 2017 elaboraram nove açóes respectivamente e 2018 dez ações.

Com relação aos dados de 2016, constatou-se que das nove açôes elaboradas $100 \%$ cumpriram com a perspectiva ética, $67 \%$ contemplaram iniciativas econômicas e em 55\% apresentaram aspectos legais e filantrópicos. No ano de 2017 observou-se que das nove açôes desenvolvidas, 100\% contemplaram 
o caráter ético, 78\% estavam cumprindo com a legalidade dos programas, $67 \%$ receberam investimentos financeiros atendendo a perspectiva econômica e em 55\% dos programas atenderam aos aspectos filantrópicos. Com base nos relatórios de 2018 constatou-se que dos dez programas elaborados naquele ano, $90 \%$ cumpriram o carácter ético, $70 \%$ estavam em conformidade com a perspectiva econômica e legal, bem como em $50 \%$ constatou aspectos da filantropia.

Desta forma, pode-se concluir que em todas as ações apresentadas nos relatórios da companhia foram evidenciadas alguma das percepçôes de RSE, destacando que em 2016 três açóes cumpriram com todas as perspectivas de RSE, e nos anos de 2017 e 2018 apresentaram-se quatro açóes que cumpriram $100 \%$ da teoria de Carroll.

No desenvolvimento do estudo constatou como um dos limitadores a falta de informação quanto aos programas desenvolvidos pela companhia, sendo que apesar do estudo contemplar a análise do relatório anual e de sustentabilidade as informaçóes que constavam nesses eram limitadas, fornecendo poucos dados quanto a forma que os projetos eram desenvolvidos. Destaca-se ainda, que todo estudo é pautado exclusivamente na análise de documentos, caracterizando este como um limitador da pesquisa, visto a impossibilidade de verificar a exatidão no cumprimento das açóes e projetos descritos nos relatórios.

Como sugestão de pesquisas futuras sugere-se a análise dos relatórios de um período maior para identificar a continuidade dos programas desenvolvidos, além de inserir a análise de outros dados divulgados pelas organizaçóes para ampliar o portfólio de informação das açóes desenvolvidas.

\section{Referências}

ABNT. Introdução à ABNT NBR ISO 14.001:2015. São Paulo: ABNT, 2015.

ABNT. NBR 10.004. Rio de Janeiro: ABNT, 2004. Disponível em: https://www.abntcatalogo.com.br/ norma.aspx?ID=936. Acesso em: 28 out. 2020.

ANDRADE, Marcelo Aureliano Monteiro de; GOSLING, Marlusa; XAVIER, Wescley Silva. Por trás do discurso socialmente responsável da siderurgia mineira. Produçáo, v.20, n. 3, p. 418-428, 2010.

ANP. Agência Nacional de Petróleo, Gás Natural e Biocombustível. Disponível em: < http://www. anp.gov.br>. Acesso em: 27 out. 2018.

APPIO, Jucelia; MADRUGA, Bruna Passaúra; FRIZON, Nelson Natalino. Responsabilidade Social Empresarial: um estudo de caso à luz da concepção piramidal de Archie Carroll. Sistemas \& Gestáo, v. 13, n. 3, p. 394-401, 2018.

ASHLEY, Patrícia Almeida. Ética e responsabilidade social nos negócios. São Paulo: Saraiva, 2002.

BENEDICTO, Samuel Carvalho de; RODRIGUES, Ângelo Constâncio; PENIDO, Aline Micheli da Silva. Surgimento e evolução da responsabilidade social empresarial: uma reflexão teórico-analítica. XXVIII Encontro Nacional de Engenharia de Produçáo. Rio de Janeiro, 2008. 
BITTENCOURT, Epaminondas; CARRIERI, Alexandre. Responsabilidade social: ideologia, poder e discurso na lógica empresarial. Revista de Administração de empresas, v. 45, n. SPE, p. 10-22, 2005.

BOWEN, Howard Rothmann. Responsabilidades sociais do homem de negócios. Rio de Janeiro: Editora Civilização Brasileira, 1957.

BRASIL. Lei 6.938. Dispóe sobre a Política Nacional do Meio Ambiente, seus fins e mecanismos de formulação e aplicação, e dá outras providências. 1981. Disponível em: http://www.planalto.gov.br/ ccivil_03/leis/16938.htm. Acesso em: 28 out. 2020.

BRASIL. Lei 8.313. Restabelece princípios da Lei $n^{\circ} 7.505$, de 2 de julho de 1986, institui o Programa Nacional de Apoio à Cultura (Pronac) e dá outras providências. 1991. Disponível em: http://www. planalto.gov.br/ccivil_03/leis/18313cons.htm. Acesso em: 28 out. 2020.

BRASIL. Lei 9.433. Institui a Política Nacional de Recursos Hídricos, dentre outros. 1997. Disponível em: http://www.planalto.gov.br/ccivil_03/leis/19433.htm\#: - :text=L9433\&text=LEI\%20 N\%C2\%BA\%209.433\%2C\%20DE\%208\%20DE\%20JANEIRO\%20DE\%20

1997.\&text=Institui\%20a\%20Pol\%C3\%ADtica\%20Nacional\%20de,Federal\%2C\%20e\%20altera\%20 o\%20art. Acesso em: 28 out. 2020.

BRASIL. Lei 9.605.- Dispóe sobre as sançóes penais e administrativas derivadas de condutas e atividades lesivas ao meio ambiente, e dá outras providências. 1998. Disponível em: http://www. planalto.gov.br/ccivil_03/leis/19605.htm. Acesso em: 28 out. 2020.

BRASIL. Lei 11.438. Dispóe sobre incentivos e benefícios para fomentar as atividades de caráter desportivo e dá outras providências. 2006. Disponível em: http://www.planalto.gov.br/ccivil_03/_ ato2004-2006/2006/lei/l11438.htm. Acesso em: 28 out. 2020.

BRASIL. Lei 12.305. Institui a Política Nacional de Resíduos Sólidos; altera a Lei no 9.605, de 12 de fevereiro de 1998; e dá outras providências.2010. Disponível em: http://www.planalto. gov.br/ccivil_03/_ato2007-2010/2010/lei/112305.htm\#:-:text=LEI\%20N\%C2\%BA\%20 $12.305 \% 2 \mathrm{C} \% 20 \mathrm{DE} \% 202 \% 20 \mathrm{DE} \% 20$ AGOSTO\%20DE\%202010.\&text=Institui\%20 a\%20Pol\%C3\%ADtica\%20Nacional\%20de, 1998\%3B\%20e\%20d\%C3\%A1\%20outras\%20 provid\%C3\%AAncias. \&text=Art.\&text=\%C2\%A7\%202o\%20Esta\%20Lei,s\%C3\%A3o\%20 regulados\%20por\%20legisla\%C3\%A7\%C3\%A3o\%20espec\%C3\%ADfica. Acesso em: 28 out. 2020.

BRASIL. Lei 12.846. Dispóe sobre a responsabilização administrativa e civil de pessoas jurídicas pela prática de atos contra a administração pública, nacional ou estrangeira, e dá outras providências. 2013. Disponível em: http://www.planalto.gov.br/ccivil_03/_ato2011-2014/2013/lei/112846.htm. Acesso em: 28 out. 2020.

CAMARGO, Ana Luiza de Brasil. Desenvolvimento sustentável: dimensóes e desafios. Papirus, 2005.

CARROLL, Archie B. A three-dimensional conceptual model of corporate performance. Academy of management review, v. 4, n. 4, p. 497-505, 1979. 
CARROLL, Archie B. The pyramid of corporate social responsibility: Toward the moral management of organizational stakeholders. Business horizons, v. 34, n. 4, p. 39-48, 1991.

sustentaveis/>. Acesso em 28 out. 2018.

FERREL, O. C.; FRAEDRICH, John; FERREL, L. Ética empresarial: dilemas, tomadas de decisóes e casos Trad. Cecília Arruda, v. 4, 2001.

FLICK, Uwe. Introdução à pesquisa qualitativa. 3. ed. Porto Alegre: Artmed editora, 2008.

GEORGE, Richard T. de. The status of business ethics: past and future. Journal of Business ethics, v. 6, n. 3, p. 201-211, 1987.

GIL, Antônio Carlos. Métodos e técnicas de pesquisa social. 6. ed. Sáo Paulo: Atlas, 2008.

GOMES, J. A.; SOUSA, J. L. R.; ABREU, C. B.; SOUSA FILHO, J. M. Comportamento de Responsabilidade Social Empresarial: Análise dos Projetos Realizados no Varejo Supermercadista Brasileiro. Revista de Gestáo Social e Ambiental, v. 9, n. 2, p. 23-37, 2015.

INSTITUTO ETHOS. Indicadores de Responsabilidade Social Empresarial. São Paulo: Instituto Ethos, 2007. Disponível em:< https://www3.ethos.org.br/wp-content/uploads/2013/07/ IndicadoresEthos_2013_PORT.pdf> Acesso em: 14 de set. 2018.

INSTITUTO AKATU. Pesquisa Akatu: Consumidor valoriza práticas empresariais sustentáveis. São Paulo: Instituto Akatu, 2013. Disponível em:< https://www.akatu.org.br/noticia/pesquisa-akatuconsumidor-valoriza-praticas-empresariais-

LAVILLE, Jean-Louis. Fato associativo e economia solidária. Bahia Análise e Dados, Salvador, Superintendência de Estudos Econômicos e Sociais da Bahia, v. 12, n. 1, p. 25-34, 2002.

MACÊDO, Nívea M. M. Nascimento; CÂNDIDO, Gesinaldo Ataíde. Identificação das percepçôes de responsabilidade social empresarial: um estudo qualitativo a partir da aplicação do modelo conceitual tridimensional de performance social. Revista de Gestáo Social e Ambiental, v. 5, n. 1, 2011.

MANINI, Miriam Paula. Análise documentária de fotografias: um referencial de leitura de imagens fotográficas para fins documentários. Sáo Paulo: Universidade de Sáo Paulo, 2002.

MATSUSHITA, M. A influência dos valores dos gestores no papel de recursos humanos. 2004. Tese de Doutorado. Dissertação de Mestrado, Universidade Presbiteriana Mackenzie, São Paulo.

MELO NETO, Francisco Paulo de; FROES, César. Responsabilidade social e cidadania empresarial: a administração do terceiro setor. Rio de Janeiro: Qualitymark, 1999.

MELO, Mario Fernando de; MELO, Arthur Zago De. Uma análise das práticas de Responsabilidade Social e Sustentabilidade como estratégias de empresas industriais do setor moveleiro: um estudo de caso. Gestáo e Produçáo, v. 25, n. 1, p. 81-93, 2018. 
NAKAYAMA, Regina Mitiko; TEIXEIRA, Rivanda Meira. Ações de responsabilidade social com relação ao Stakeholder fornecedor: estudo de caso baseado nos indicadores Ethos em uma empresa brasileira do setor de cosméticos. Revista Contabilidade, Gestáo e Governança, v. 15, n. 1, 2012.

PEREIRA, Isabel Maria Garcia Alves.A responsabilidade social das empresas e o seu impacto. 2016. Dissertaçáo. (Mestrado em Direito de Empresas). Instituto Universitário de Lisboa. Portugal.

PETROBRÁS. Petróleo Brasileiro S.A. Disponível em: < http://www.Petrobrás.com.br>. Acesso em: 27 out. 2018.

TENÓRIO, Organizador Fernando Guilherme. Responsabilidade social empresarial: teoria e prática. Editora FGV, 2015.

TOZZO, Bruna Pelegrini; IGARASHI, Deisy C. Corrêa; IGARASHI, Wagner; SILVA, Queren L. R. Faustino da. Percepçóes de responsabilidade social empresarial propostas por Carroll: análise do relatório de sustentabilidade de empresas do setor de energia elétrica. Revista Competitividade e Sustentabilidade, v. 4, n. 2, p. 46-65, 2017. 